\title{
Synthesis, model and stability of helically coiled carbon nanotubes
}

Fejes, Dora; Raffai, Manuella; Hernadi, Klara; Popovic, Zoran P.; Damnjanovic, Milan; Milocsevic, Ivanka; Balogh, Zoltan Imre

Published in:

E C S Solid State Letters

Link to article, DOI:

$10.1149 / 2.003303 s s \mid$

Publication date:

2013

Document Version

Publisher's PDF, also known as Version of record

Link back to DTU Orbit

Citation (APA):

Fejes, D., Raffai, M., Hernadi, K., Popovic, Z. P., Damnjanovic, M., Milocsevic, I., \& Balogh, Z. I. (2013).

Synthesis, model and stability of helically coiled carbon nanotubes. E C S Solid State Letters, 2(3), M21-M23.

https://doi.org/10.1149/2.003303ssl

\section{General rights}

Copyright and moral rights for the publications made accessible in the public portal are retained by the authors and/or other copyright owners and it is a condition of accessing publications that users recognise and abide by the legal requirements associated with these rights.

- Users may download and print one copy of any publication from the public portal for the purpose of private study or research.

- You may not further distribute the material or use it for any profit-making activity or commercial gain

- You may freely distribute the URL identifying the publication in the public portal 


\title{
Synthesis, Model and Stability of Helically Coiled Carbon Nanotubes
}

\author{
Dora Fejes, ${ }^{a}$ Zoran P. Popović, ${ }^{b}$ Manuella Raffai, ${ }^{a}$ Zoltan Balogh, ${ }^{\mathrm{c}}$ Milan Damnjanović, \\ Ivanka Milošević, ${ }^{\mathrm{b}, *, \mathrm{z}}$ and Klara Hernadi ${ }^{\mathrm{a}}$ \\ ${ }^{a}$ Department of Applied and Environmental Chemistry, University of Szeged, H-6720 Szeged, Hungary \\ ${ }^{b}$ NanoLab, Faculty of Physics, University of Belgrade, 11001 Belgrade, Serbia \\ ${ }^{c}$ Center for Electron Nanoscopy, Technical University of Denmark, 2800 Lyngby, Denmark
}

\begin{abstract}
Structural model of helically coiled carbon nanotubes is proposed. It is constructed by means of topological coordinate method. Relaxation and cohesive energy calculation are performed by molecular mechanics, using second-generation bond order potential for hydrocarbons introduced by D. W. Brenner. Our experiments focused on the production and development of catalysts for the synthesis of helically coiled CNTs (carbon nanotubes). The catalysts were tested in the decomposition of acetylene by CCVD (Catalytic Chemical Vapor Deposition) method. The carbon deposit was imaged by TEM (Transmission Electron Microscopy), HRTEM (High Resolution Transmission Electron Microscopy).
\end{abstract}

(C) 2012 The Electrochemical Society. [DOI: 10.1149/2.003303ssl] All rights reserved.

Manuscript submitted November 7, 2012; revised manuscript received December 10, 2012. Published December 27, 2012. This was Paper 1197 presented at the Seattle, Washington, Meeting of the Society, May 6-10, 2012.

The existence of helically coiled carbon nanotubes was first predicted by Ihara et al. ${ }^{1}$ and Dunlap ${ }^{2}$ in the early nineties and a few years later a Belgian research group reported their experimental observation. ${ }^{3}$ Recently, we reviewed ${ }^{4}$ regularly coiled carbon nanotubes, their synthesis, their structure, formation mechanism, and theoretical aspects, giving an up-to-date summary of scientific results accumulated until now on this field.

Here we present a technique of construction of atomistic models of helically coiled carbon nanotubes (HCCNTs) based on the topological coordinate method which uses triple connected graphs of pentagons, hexagons and heptagons ${ }^{5,6}$ as well as the synthesis and characterization of coiled carbon nanotubes. This technique overcomes the shortcomings of the previously proposed methods in which the coils are built out of particular fullerene ${ }^{1}$ or out of particular straight singlewall CNT, ${ }^{2,7}$ getting thus only a few different tubes helical diameter of which reaches two nanometers at most (i.e. several orders of magnitude less than the average coil diameter of the CCVD grown tubes).

Stability of the obtained models of the helically coiled CNTs is verified: their cohesive energy is calculated after performing molecular dynamic relaxation based on the second-generation reactive empirical bond order Brenner potential for solid carbon structures. ${ }^{8}$

We investigated the effect of the $\mathrm{pH}$ during the wet milling catalyst preparation process, we calculated the carbon yield of the catalysts, and characterized the coil structures more in detail by measuring the dimensions of these coils after catalytic carbon nanotube synthesis. We observed the morphology of helically coiled carbon nanotubes by TEM and HRTEM.

\section{Modeling}

SWCNTs (Single Walled Carbon Nanotubes) can be obtained by identifying a pair of the opposite edges of a parallelogram cut out from a graphene sheet. Positive and negative Gaussian curvatures in the carbon structures arise from substitution of some hexagons by pentagons and heptagons, respectively. Thus, in order to construct helical nanotube structure we start with three-coordinated periodical stylized tiling of the plane by heptagons, hexagons and pentagons and apply the procedure of building up a helical tubular structure, based on the topological coordinate method..$^{5}$ After getting three-dimensional coordinates of the carbon atoms of a helically coiled CNT we proceed with relaxation. Final relaxed structure depends on the tiling and on the super-cell position. Hence, we start with particular tiling and super-cell and construct series of graphs and super-cells by further insertion of horizontal and vertical stripes of hexagons, between the

\footnotetext{
*Electrochemical Society Active Member.
}

${ }^{z}$ E-mail: ivag@rcub.bg.ac.rs pentagons and heptagons or between the twin columns of heptagons in order to enlarge tubular diameter and indirectly, through process of relaxation, enlarging also diameter of a coil and changing helical angle and helical step as well. ${ }^{6}$

Helically coiled CNT is constructed from the graph defined as follows (more detailed description of the model is given in Ref. 6): $\left(n_{6}, n_{r}, n_{7}, n_{5},\left(\boldsymbol{b}_{1}, \boldsymbol{b}_{2}\right)\right)$, where $\boldsymbol{b}_{1}$ and $\boldsymbol{b}_{2}$ are the super-cell vectors, $n_{r}$ is number of rows of hexagons added above a single LR (LaszloRassat $)^{5}$ cell $\left(n_{6},(1,0),(0,1)\right), n_{7}$ and $n_{5}$ are numbers of columns of hexagons inserted between the columns of heptagons and pentagons, respectively (Figure 1). Three series of helically coiled CNTs defined by the $n_{5}$ parameter are shown in Figure 2. This parameter defines radial position of pentagons, i.e. their distance from the helical axis. Helical diameter increases and helical step decreases with $n_{5}$, when $n_{6}$ and $n_{r}$ are fixed. Within each of the series particular tubes are defined by parameters $n_{6}$ and $n_{r}$ which are here set equal and are taking the values $1,3,5,7$ and 9 . The super-cell vectors are $\boldsymbol{b}_{1}=(1,0)$ and $\boldsymbol{b}_{2}$ $=(0,5)$ and there is no separation of the columns of heptagons of the original LR cell (i.e. $n_{7}=0$ ). Within each of the series tubular and helical diameter increase linearly with $n_{6}=n_{r}$, as well as the monomer length $a$.

However, if $n_{6} \neq n_{r}$ and the value of $n_{6}$ is fixed, the helically coiled CNTs constructed out of such graphs mutually differ by the size of the helical diameter and helical step (the both increase with $n_{\mathrm{r}}$ ) while tubular diameters of these coils do not differ appreciably. Oppositely, if $n_{\mathrm{r}}$ is fixed, helical and tubular diameter increase with $n_{6}$ while the inclination decreases.

Different choices of the super-cell, within the same tiling, have considerable impact on the overall structure of the helically coiled tube. Particular choice of the super-cell defines orientation of the polygons relative to the nanotube axis while concentration of pentagons and heptagons is determined by the tiling only. However, fine tuning of the geometrical parameters of the coiled nanotube cannot be achieved by taking different super-cell vectors on the same tilling. Engineering of the structural features of the helically coiled CNTs is easier to control when the type of the super-cell remains the same while the tiling is changed gradually. Characteristic structural data of the ensemble of 218 modeled helically coiled CNTs is summarized in Table I.

\section{Experimental}

Preparation of the catalysts for the synthesis of coiled carbon nanotubes.- Here we apply wet milling with distilled water and with ammonia solution, they provide slightly acid and basic environment, respectively. During the wet milling process $0.2469 \mathrm{~g}$ of the precursor $\left(\mathrm{Co}\left(\mathrm{NO}_{3}\right)_{2}\left(\mathrm{H}_{2} \mathrm{O}\right)_{6}\right.$, Sigma-Aldrich), $0.95 \mathrm{~g}$ of the support (13X 


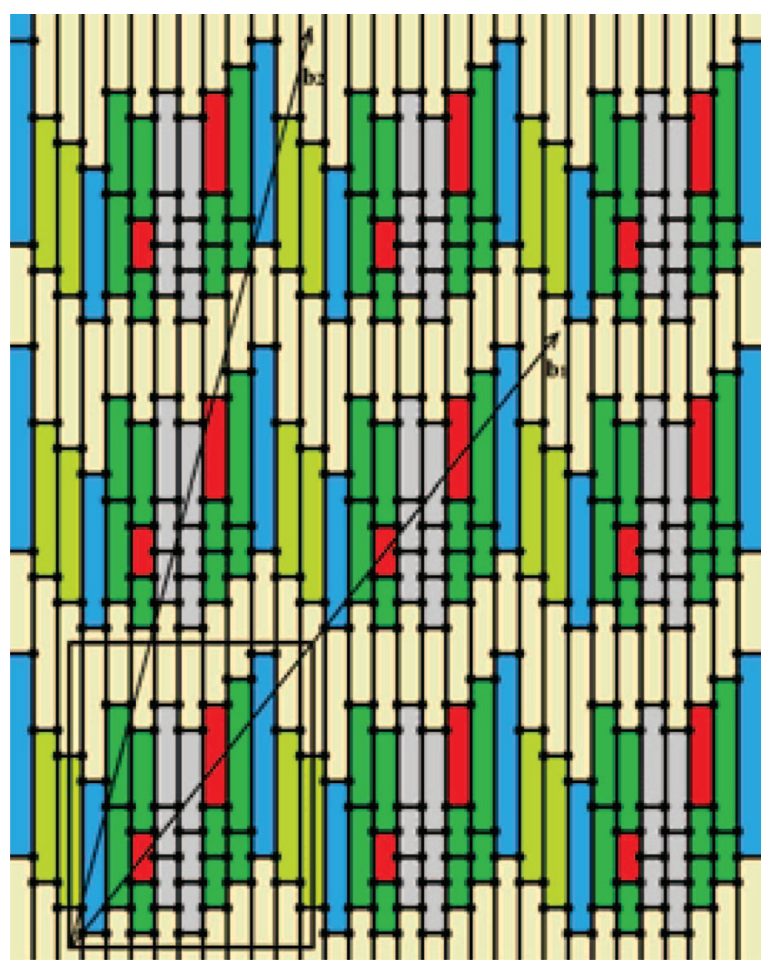

Figure 1. (Color online) Graph $\left(n_{6}, n_{r}, n_{7}, n_{5},\left(\boldsymbol{b}_{1}, \boldsymbol{b}_{2}\right)\right)=(1,1,2,2,((2,2),(1,3)))$ : tiling of the plane by heptagons, pentagons and hexagons where one row of hexagons is added at the top of the original LR cell and columns of heptagons and pentagons are separated by two stripes of hexagons, each. Super-cell vectors $\boldsymbol{b}_{1}$ and $\boldsymbol{b}_{2}$ are represented by the arrows and the unit cell by the rectangle.

zeolite, UOP Fluka) and $2 \mathrm{~mL}$ distilled water or $25 \% \mathrm{NH}_{4} \mathrm{OH}$ were mixed mechanically in a Pulverisette 6 type planetary ball mill (in air), equipped with a $250 \mathrm{~mL}$ grinding bowl. As-prepared catalysts contained $5 \%$ metal. Each time 8 balls of $20 \mathrm{~mm}$ size were used for homogenization. The rotational speed was $450 \mathrm{rpm}$, the respective treatment times of planetary ball milling were 60 minutes.

CCVD Synthesis of helically coiled carbon nanotubes. - Carbon nanotubes were grown catalytically by acetylene decomposition at $720^{\circ} \mathrm{C}$ for $30 \mathrm{~min}$ in a fixed-bed flow reactor using gas feed of nitrogen $(500 \mathrm{~mL} / \mathrm{min})$ and acetylene $(10 \mathrm{~mL} / \mathrm{min})$. In order to give some quantitative characterization of the catalytic decomposition of acetylene, carbon yield was calculated as follows:

$$
\text { Carbon yield }(\%)=100\left(\mathrm{~m}_{\mathrm{tot}}-\mathrm{m}_{\text {cat }}\right) / \mathrm{m}_{\text {corr.cat }}
$$

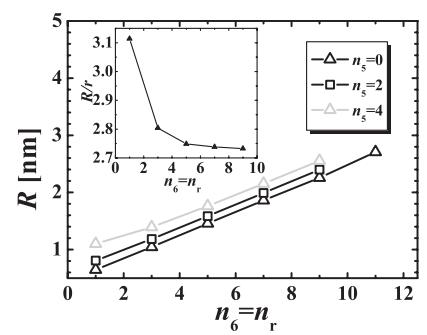

(a)

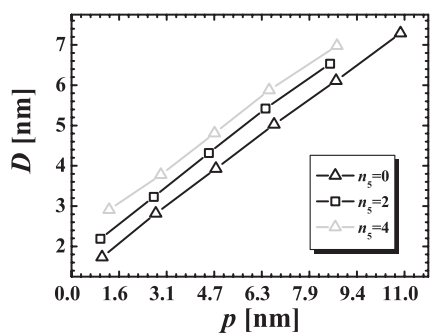

(b)
Figure 2. Within each of the three series (defined by the value of $n_{5}=0,2$ and 4) of helically coiled CNTs $n_{6}=n_{r}$ dependence of the helical radius $R$ (a) and helical diameter $D$ and step $p$ (b) are shown. Inset of (a) gives $n_{\mathrm{r}}$-dependence of the helical $R$ and tubular $r$ radii ratio (for the series defined by $n_{5}=4$ ).

\section{Table I. Range of diameters, inclination angles and length data} of the ensemble of 218 modeled helically coiled carbon nanotubes.

Characteristic data

Helix diameter $D$
Coil pitch $p$
Tube diameter $d$
Tube length
Inclination angle $\chi$
Monomer length $a$
$D / d$

$1.2 \mathrm{~nm}-44.0 \mathrm{~nm}$

$0.3 \mathrm{~nm}-14.9 \mathrm{~nm}$

$0.4 \mathrm{~nm}-3.4 \mathrm{~nm}$

Infinite

$5^{\circ}-64^{\circ}$

$0.8 \mathrm{~nm}-10.8 \mathrm{~nm}$ $0.9-31$

where, $\mathrm{m}_{\text {cat }}$ is the initial mass of the catalyst immediately before the reaction, $\mathrm{m}_{\text {tot }}$ is the total weight of the sample after reaction, $\mathrm{m}_{\text {corr.cat }}$ is the corrected mass of the catalyst after weight loss at the temperature of CCVD reaction $\left(720^{\circ} \mathrm{C}\right)$. We calculated carbon yield instead of CNT yield because oxidative purification could be carried out, however, it would result in the complete elimination of coiled carbon nanotubes. ${ }^{9}$ Additionally the essence of CCVD method is the selective production of CNTs, so only small amount of amorphous carbon can be formed during the synthesis.

\section{Experimental Results}

Nanosized particles generated from the solid surface during grinding tend to form agglomerate instantaneously and become stable, coarser particles. In this way, it is very difficult to produce stable nanosized particles by dry grinding method, since active nanoparticles from fresh agglomerates as soon as they contact each other. Therefore, the grinding has to be carried out in a liquid (wet milling). In the wet milling process, as the surface of the generated particle is surrounded by a solvent instantaneously, it is possible to control the agglomeration of particles much better than in the dry milling, ${ }^{10}$ furthermore the $\mathrm{pH}$ (or the organic nitrogen content) of the solution during catalyst preparation has a significant role on the resulted structure. Figure 3a shows the result of the wet milling with distilled water, the as-prepared sample consist of irregular nanotubes, while Figure $3 \mathrm{~b}$ represents the coiled carbon nanotubes prepared by using wet milling with ammonia solution. The calculated carbon yield was $30.09 \%$ in case of preparing the catalyst with distilled water, and $39.1 \%$ with ammonia solution. Figure 4 summarizes the outer diameter distribution of the as-prepared helically coiled carbon nanotubes, mainly they are in the range of 10-20 nm. To compare the characteristic data with the theoretical ones, we characterized the helix diameter, coil pitch, tube diameter and tube length of the coiled carbon nanotubes (Table II), quantitatively most of the characteristic parameters are nearly close to the dimesions of the modeled helically coiled carbon nanotubes. The helix diameter is overlapping, but the modeled coil pitch and tube

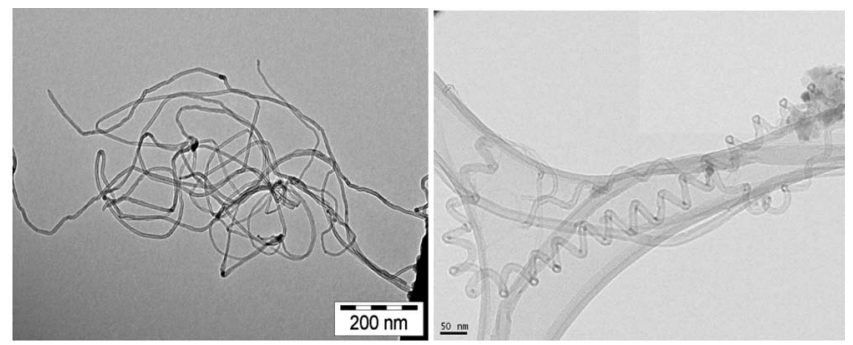

(a)

(b)

Figure 3. Figure 3(a) shows the result of the wet milling with distilled water, the as-prepared sample consist of irregular nanotubes, while figure 3(b) represents the coiled carbon nanotubes prepared by using wet milling process with ammonia solution. Here the dimensions of the helically coiled carbon nanotube are the follows: the helix diameter is $58 \mathrm{~nm}$, the coil pitch is $55 \mathrm{~nm}$, the tube diameter is $13 \mathrm{~nm}$ and the tube length is $1114 \mathrm{~nm}$. 


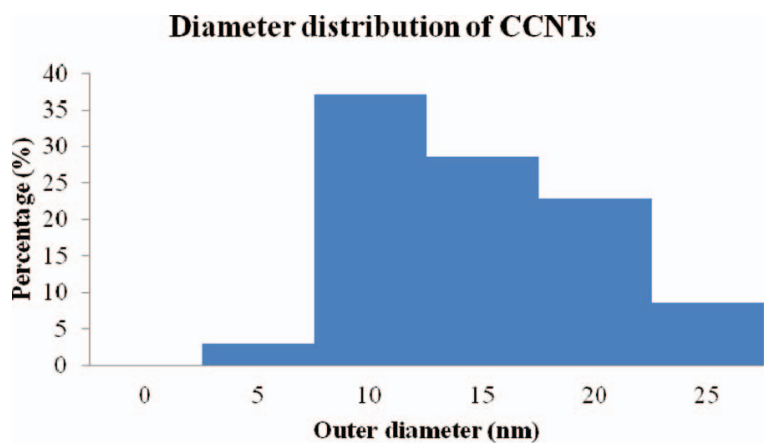

Figure 4. Figure 4 summarizes the outer diameter distribution of the asprepared helically coiled carbon nanotubes, mainly they are in the range of $10-20 \mathrm{~nm}$.

diameter is smaller than the synthesized ones. Our theoretical model is single-walled in contrast to the multi-walled structure of the real tubes. On one hand the cell of the model is limitated by number of atoms, on the other hand, has not been reported on the synthesis of single-walled helically coiled nanotubes according to our knowledge. To bring even better agreement we should succeed in the synthesis of single-walled helically coiled CNTs.

\section{Stability}

Relaxation and cohesive energy calculations are performed by molecular mechanics based on the bond order potential for hydrocarbons developed by D. W. Brenner. ${ }^{8}$ Application of the symmetry made the relaxation procedure more efficient. As to the generators of the symmetry of the helically coiled CNTs,${ }^{6}$ apart from the screw axis transformation, pertains also a rotation for $\pi$ around the axis perpendicular to the helical axis, relaxation can be restricted just to a half of the monomer. The Hooke-Jeeves algorithm ${ }^{11}$ is used, as here it proved to give the best minima and to be reasonably fast.

Within the series of helically coiled CNTs, cohesive energy increases with the tubular and helical diameter and saturates eventually. The calculated values are between $6.7 \mathrm{eV} / \mathrm{atom}$ and $7.2 \mathrm{eV} / \mathrm{atom}$. In Figure 5, tubular and helical diameter dependence of the energies calculated for the series $\left(n, n, 0, n_{5},((1,0),(0,5))\right), n_{5}=0,2,4$ and $n$ $=1,2, \ldots, 11$, of helically coiled CNTs are presented. Tubes of these series mutually differ by the number of stripes of hexagons $n_{5}$ inserted between the columns of pentagons, by the number of columns of hexagons $n_{6}=n$ which separate pentagons from heptagons and by the number of rows of hexagons $n_{r}=n$ added to the initial LR cell. Pentagon and heptagon concentration per monomer decreases with $n$.

For the sake of comparison, dependence of the cohesive energy on the tubular radius of the straight single-walled CNTs has been calculated by the same method. The fitted $E(r)$ function, Figure $5 \mathrm{a}$, when up shifted for $200 \mathrm{meV}$ represents also a good fit of the cohesive energies of the helically coiled CNTs. Infinite radius limit of the energy of SWCNTs which according to our calculation is $7.394 \mathrm{eV}$ matches the recently reported ${ }^{12}$ value of the graphene cohesive energy, obtained by applying the same, original Brenner, potential. The values of the cohesive energy obtained by DFTB (density functional tight binding) method $^{13}$ are generally somewhat larger than the values obtained by

Table II. Range of diameters, coil pitches, length data of the as-synthesized helically coiled carbon nanotubes.

Characteristic data

Helix diameter $D$

$30.0 \mathrm{~nm}-88.0 \mathrm{~nm}$

Coil pitch $p$

Tube diameter $d$

Tube length

$31.0 \mathrm{~nm}-53.2 \mathrm{~nm}$

$9.6 \mathrm{~nm}-29.2 \mathrm{~nm}$

$150 \mathrm{~nm}-700 \mathrm{~nm}$

$D / d$
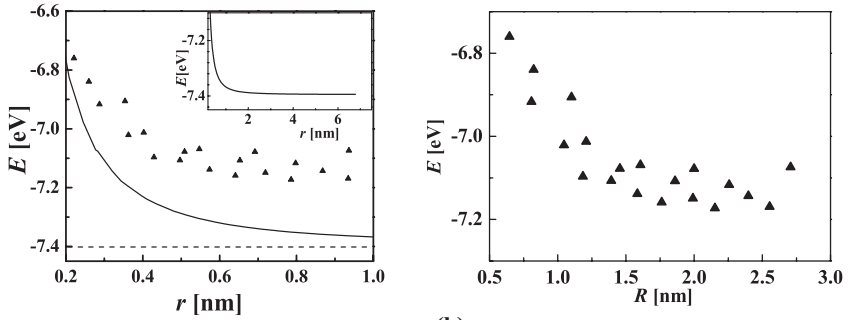

(b)

Figure 5. (a) Cohesive energy $E$ of helically coiled CNTs as a function of tubular radius $r$ : Black triangles represent data for the series of helically coiled CNTs $\left(n, n, 0, n_{5},((1,0),(0,5))\right)$, where $n_{5}=0,2,4$ and $n=1,2,3 \ldots ., 11$; solid line shows the data for the straight SWCNTs calculated using the same bond order potential; dashed horizontal line at $-7.394 \mathrm{eV}$ indicates the infinite radius limit of the cohesive energy of SWCNTs. Inset: $E(r)$-dependence over wider tubular radii range of helically coiled CNTs. (b) Helical radius $R$ dependence of the cohesive energy $E$ of helically coiled CNTs. Calculated values of the above defined series of the coiled nanotubes are presented.

the method applied here. For instance, in Ref. 6, where the symmetry based DFTB calculations are performed, cohesive energy of the helically coiled CNTs is from $7.46 \mathrm{eV} /$ atom to $8.00 \mathrm{eV} /$ atom, while the energies of graphene and $(10,10)$ nanotube are $9.70 \mathrm{eV} /$ atom and $8.27 \mathrm{eV} /$ atom, respectively.

\section{Conclusion}

By the technique presented here we are able to build helically coiled CNTs within the wide range of geometrical parameters and also within considerably large interval of the tubular-helical lateral sizes ratio (Table I). Control over the structural features of the coils is gained by picking particular tiling of the plane and by choosing appropriate super-cell vectors.

Final structural model has smooth helical profile and circular cross section, qualitatively matching the as-synthesized helically coiled CNTs. Quantitatively most of the characteristic parameters are nearly close to the dimesions of the CCVD grown carbon coils (Table II). Nevertheless, our theoretical model is single-walled in contrast to the multi-walled structure of the real tubes.

\section{Acknowledgments}

This work was supported by the Swiss National Science Foundation (IZ73Z0_128037/1), Klara Hernadi and Dora Fejes thank the support for the Hungarian Science Foundation (OTKA KM1 15 T K 76125). Milan Damnjanović, Zoran P. Popović and Ivanka Milošević acknowledge funding of Serbian Ministry of Science (ON171035).

\section{References}

1. S. Itoh, S. Ihara, and J. Kitakami, Phys. Rev. B, 48, 5643 (1993).

2. B. I. Dunlap, Phys. Rev. B, 46, 1933 (1992).

3. X. B. Zhang, X. F. Zhang, D. Bernaerts, G. Van Tendeloo, S. Amelinckx, J. Van Landuyt, V. Ivanov, J. B. Nagy, P. Lambin, and A. A. Lucas, Europhys. Lett., 27, 141 (1994).

4. D. Fejes and K. Hernadi, Materials, 3, 2618 (2010).

5. I. Laszlo and A. Rassat, J. Chem. Inf. Comput. Sci., 43, 519 (2003).

6. I. Milosevic, Z. P. Popovic, and M. Damnjanovic, Phys. Stat. Solidi B, 249, 2442 (2012).

7. L. Z. Liu, H. L. Gao, J. J. Zhao, and J. P. Lu, Nanoscale Res. Lett., 5, 478 (2010).

8. D. W. Brenner, O. A. Shenderova, J. A. Harrison, S. J. Stuart, B. Ni, and S. B. Sinnott, J. Phys. C, 14, 783 (2002).

9. K. Hernadi, A. Siska, L. Thie^n-Nga, L. Forro, and I. Kiricsi, Solid State Ionics, 141-142, 203 (2001)

10. D. Fejes, L. Forró, and K. Hernadi, Phys. Stat. Solidi B, 247, 2713 (2010).

11. R. Hooke and T. A. Jeeves, JACM, 8, 212 (1961).

12. L. Lindsay and D. A. Broido, Phys. Rev. B, 81, 205441 (2010).

13. D. Porezag, Th. Fraunheim, Th. Kohler, G. Seifert, and R. Kaschner, Phys. Rev. B, 51, 12947 (1995). 